\title{
Forecasting Movement of Stock Index - Use \\ Of Spread between E/P Ratio and Interest Rate
}

\author{
Dr. Sathya Swaroop Debasish \\ P.G. Department of Business Management \\ FAKIR MOHAN UNIVESITY \\ Vyasa Vihar, Balasore-19 \\ Orissa, INDIA
}

Tel: 91-9437284361Ｅ-mail: sathyaswaroop2000@yahoo.com

\author{
Dr. Bhagaban Das (Corresponding Author) \\ P.G. Department of Business Management \\ FAKIR MOHAN UNIVESITY \\ Vyasa Vihar, Balasore-19 \\ Orissa, INDIA \\ Tel: 91-9437131429Ｅ-mail: Bhagaban_Fm@Yahoo.Co.In
}

\begin{abstract}
The earnings-price ratio (E/P ratio) of the NSE Nifty index and the spreads between the E/P ratio and interest rates are widely used by market practitioners to forecast the stock market outlook. The present paper employs several statistical and econometric tools (viz., correlation analysis, regression analysis, Granger's causality test and measures of out-of-sample forecast performance) for rigorously assessing the usefulness of spread in explaining stock market return in India. The database includes the weekly and monthly closing values of NSE Nifty index over the period January 5 , 1997 to December 31, 2007 (11 years). The two measures of interest rate considered are Bank rate and call money rate. Empirical results reveal that spread seems to have reasonably strong causal influence on return and the causal model helps achieving forecasts slightly better than the random walk model.
\end{abstract}

Keywords: Stock market, Granger's Causality, E/P ratio, NSE Nifty, Cross-correlation, Regression, Efficient Market Hypothesis, Random Walk

\section{Introduction}

Trading in stock market indices has gained popularity in major financial markets around the world. Accurate predictions of stock market indexes are important for many reasons. Chief among these are the need for the investors to hedge against potential market risks, and opportunities for speculators and arbitrageurs to make profit by trading in stock index. Clearly, being able to accurately forecast the stock market index has profound implications and significance for both researchers and practitioners. There exist vast literatures which concentrate on the predictability of stock market return. In almost all cases, the performance metrics and the acceptability of the proposed models are measured by the deviations of forecast value from the actual values. Different dealers, investors, and other market players adopt different trading strategies, so the forecasting models which rank first in terms minimization of forecast error may not be suitable to meet the expectation of the dealers or investors. It is because the trading driven by a particular forecasting model with a minimal forecast error may not be profitable as trading guided by an accurate prediction of the direction of movement of stock index. Therefore it is very important to forecast the direction of movement of stock index for developing effective market trading strategies.

There exists vast research articles which predict the stock market as well pricing of stock index financial instruments but most of the proposed models focus on the accurate forecasting of the levels (i.e. value) of the underlying stock index. There is a lack of studies examining the predictability of the direction/sign of stock index movement. Given the notion that a prediction with little forecast error does not necessarily translate into capital gain, an attempt is made to assess the usefulness of spread between E/P ratio and interest rate in the context of Indian stock market. For this the has taken a 
case of S\&P CNX NIFTY Market Index of the National Stock Exchange, one of the fastest growing financial exchanges in developing Asian countries.

Empirical evidence for the developed economies suggests that the information on the spread between E/P ratio at the stock market and a measure of interest rate is sometimes useful in predicting stock market movements. In case of emerging markets like India, the issue has, however, not received adequate attention. The earnings-price ratio (E/P ratio) of an individual stock is widely used by market practitioners to forecast the movement of the stock. Similarly, the E/P ratio of a stock market index is used to forecast the overall stock market outlook. The spreads between the E/P ratio and interest rates are other indicators used to monitor the stock market. These spreads are used for "market timing" such that, based on the signals generated from the spreads, a decision is made to invest in the stock market index or in bonds. The reason behind such use is that theoretically the E/P ratio and long-term interest rates should have an equilibrium relationship, as investors will arbitrage between stocks and bonds. Whenever there is a deviation from the equilibrium, stock prices will move the E/P ratio and long-term interest rates to the direction of the equilibrium. It is also noted that some central banks' financial stability reports include measures of whether stock markets are overvalued by looking at E/P ratios. This paper studies their usefulness as indicators of future Indian stock market conditions.

For analyzing the relationship between spread and return, a number of analytical tools, viz., correlation analysis, regression analysis, Granger's causality test and measures of out-of-sample forecast performance have been employed. The paper is organized into six sections. In Section 2, a brief review of literature is presented. The basic premises of considering the spread as containing advance information about stock market movement are also discussed therein. The methodology and analytical tools used in the study are presented in Section 3. Section 4 deals with describing the basic database and the derivation of measures for return and spread series in the study. In Section 5, empirical results on the relationship between spread and return are presented and interpreted. Finally, Section 6 summarizes the main findings with concluding observations.

\section{A Brief Review of Literature}

The issue of whether the spread between Earning/Price (E/P) ratio (also known as earnings yield) and interest rate contains useful information about the movement of stock market is a matter of empirical investigation in recent years (Rolph and Shen, 1999). There exists considerable evidence showing that stock returns are to some extent predictable. Most of the research is conducted using data from well established stock markets such as the US, Western Europe, and Japan. It is, thus, of interest to study the extent of stock market predictability using data from less well established stock markets such as that of India. Along with different indicators, market practitioners often use different measures of spread to analyze and predict market movements. A number of business publications in developed countries also give importance to spread in their discussions of overall market conditions and outlooks. Though a number of research papers attempted to explain/predict future stock return by considering some of the regressors among E/P ratio, yields, interest rate, earnings per share, etc., (Cutler et al, 1991; Lander et al, 1997; Mohanty, 1997; Pesaran and Timmermann, 1995; Qi, 1999; Qi and Maddala, 1999; Samanta and Rajpathak, 2001; Shiller and Campbell, 1993), the literature on direct evaluation of the usefulness of spread between E/P ratio and interest rate as an indicator for overall market outlook is at a nascent state.

An intuitive explanation on why spread may contain information about future stock market return is discussed by Rolph and Shen (1999). The information content follows from the notion that relative to the interest rate (say, it) there is an equilibrium level of spread. Under the assumption that expected future growth rate of $\mathrm{P} / \mathrm{E}$ ratio is positively related to the current spread $\left[(\mathrm{E} / \mathrm{P})_{\mathrm{t}}-\mathrm{i}_{\mathrm{t}}\right]$, a higher spread leads to higher expected growth for the $\mathrm{P} / \mathrm{E}$ ratio, which in turn gives higher expected market return. In other words, when the spread is higher than its equilibrium level, the $\mathrm{P} / \mathrm{E}$ ratio is more likely to grow faster, thus reducing the E/P ratio and spread towards its equilibrium levels and vice-versa. Basu (1977) examined the performance of various portfolios on the basis of their P/E ratios for 1957-71 and found that return on company stocks with low $\mathrm{P} / \mathrm{E}$ ratios was significantly higher that the return on companies with relatively high $\mathrm{P} / \mathrm{E}$ ratios (Keith, 1998, Page 209). Pesaran and Timmermann (1995) also used both E/P ratio and interest rates along with several other influential variables for explaining stock market movements. Lander et al (1997) also documented strong evidence that both earnings yield and interest rates matter for short-run stock market performance. They used linear combination of $\mathrm{E} / \mathrm{P}$ ratio and bond yields to predict returns on S \& $\mathrm{P} 500$ index in a regression framework.

Fuller et al. (1993) study the usefulness of E/P ratios of individual stocks in forecasting their returns. They find that stocks with high E/P ratios generate above-normal returns and those with low E/P ratios generate below-normal returns over the eighteen year period from the fourth quarter of 1973 to the third quarter of 1991, based on the US stock market data. Campbell and Shiller (1998) investigate the relationship between the E/P ratio of the S\&P 500 index and the general stock market outlook, and find that the E/P ratio at the beginning of a 10-year period is positively correlated with the return of the S\&P 500 index over that 10-year period using data from 1872 to 1997. Lander et al. (1997) find that a market-timing trading strategy based on a simple error-correction model using the expected E/P ratio of the S\&P500 index and long-term interest rates yields a higher average return with smaller volatility than that generated by 
simply buying and holding the S\&P 500 index. Rolph and Shen (1999) find that the historical extreme values of the spreads between the E/P ratio of the CRSP index in the US and the long-term and short-term interest rates contain information on the direction of the stock market. A trading rule based on the 10th percentile of the historical values of the spreads produces a higher average return (not statistically significant) and a lower variance (statistically significant) than that produced by simply buying and holding the stock market index.

In another study, Qi (1999) outlined a recursive modeling procedure to examine the predictability of S \& P 500 index returns using linear regression (LR) framework and neural network $(\mathrm{NN})$, a nonlinear framework. The explanatory variables considered by him are dividend yield, E/P ratio, 1-month Treasury Bills rate, 12-month Treasury bond rate, inflation rate, growth rate in industrial output and money growth. He found that the NN model outperforms LR-framework in terms of both within-sample fit as well as out-of-sample forecast accuracy. In the Indian context, Mohanty (1997) examined the relationship of P/E ratio and earnings per share (EPS) with stock price. Using annual data he concluded that one could make excess return by forecasting the directions of movement of EPS based on publicly available information. Use of spread variable in explaining Indian stock market return is available in Samanta and Rajpathak (2001). Though, they have not investigated detail relationship between spread and return, they constructed a composite indicator by combining partial information contents of spread in addition to E/P ratio, yields and a few other economic and financial variables, for forecasting/tracking future stock market returns.

\section{Methodologies and Analytical Tools}

For assessing the information content of spread about future stock market return, following analytical tools and methodologies are employed in the present study.

Correlation/Cross-Correlation Analysis: A preliminary assessment of the strength in relationship between return and past values of 'spread' may be assessed through appropriate correlation analysis. For this purpose, one can calculate cross-correlation coefficients between spread and returns for different orders/lags (i.e. correlation coefficient between spread and future return) and can test for their statistical significance. The cross- correlation of order $\mathrm{k}$ between spread and return (denoted by $\rho \mathrm{k}$ ) is simply the correlation coefficient between SPt-k and Rt, k being any integer. If $\rho \mathrm{k}$ 's for some positive $\mathrm{k}$, are significantly different from zero, one may expect that past values of spread would have some impact on present/future return.

Regression Analysis: The explanatory power of 'spread' in capturing the movement of stock price return could also be assessed in a regression framework. For this purpose, return series could be regressed on past information on 'spread' variable. Following Rolph and Shen (1999), the form of the regression equation may be kept simple as below.

$$
\mathrm{R}_{\mathrm{t}}=\alpha_{0}+\sum_{\mathrm{j}=1}^{\mathrm{p}} \alpha_{\mathrm{j}} \mathrm{SP}_{\mathrm{t}-\mathrm{j}}+\mathrm{e}_{\mathrm{t}}
$$

where $\mathrm{p}$ is a suitably chosen positive integer; $\mathrm{R}_{t}$ and $\mathrm{SP}_{t}$ are as defined above, $\mathrm{e}_{j}, \mathrm{j}=0,1,2, \ldots, p$ are unknown parameters and $e_{t}$ is the usual disturbance term. Some of the widely used statistics, like $R^{2}$ (i.e. adjusted- $R_{2}$ ), Durbin-Watson (D-W) statistics and Ljung-Box Q-Statistics (denoted by Q-Statistics) will be used for assessing the strength of the relationship presented in equation (1).

Granger's Causality Test: For a formal assessment of the influence/usefulness of 'spread', Granger's causality test may be performed using an extended regression equation.

$$
\mathrm{R}_{\mathrm{t}}=\alpha_{0}+\sum_{\mathrm{j}=1}^{\mathrm{P}} \boldsymbol{\alpha}_{\mathrm{j}} \mathrm{SP}_{\mathrm{t}-\mathrm{j}}+\stackrel{\mathrm{q}}{\sum} \underset{\mathrm{k}=1}{\sum \mathrm{b}_{\mathrm{k}} \mathrm{R}_{\mathrm{t}-\mathrm{k}}+\mathrm{e}_{\mathrm{t}}}
$$

As in case of equation (1), relationship presented in equation (2) may also be assessed in terms of $\mathrm{R}^{2} \mathrm{D}-\mathrm{W}$ statistics and Q-Statistics. In addition, if all $\rho_{\mathrm{j}}$ 's in equation (2) are statistically zero, the null hypothesis of no causality from spread to return is accepted. Usual F-statistics may be used for performing the causality test.

Assessing Forecast Performance: The regression diagnostics discussed above pertain to the within-sample characteristics of the data. The usefulness of 'spread' may also be assessed in terms of improvement in degree of accuracy in out-of-sample forecast of return by using spread. Therefore, it would be interesting to exploit the relationship between 'spread' and stock market return for forecasting return out-of-sample.

For this purpose, through recursive/rolling regression, forecasting exercise will be repeated several times and based on the forecast accuracy (or error in out-of-sample forecasts) in every repetition, an overall measure of forecast accuracy, say the widely used Mean Error (ME), Mean Absolute Error (MAE) and Root-Mean-Square-Error (RMSE), will be derived for different competing forecasting models, viz., (i) random walk (RW) model; (ii) regression model as in equation (1); (iii) and causal model as in equation (2). Here RW model is considered as a benchmark model to represent 
the behaviour of the stock market/prices under the weak-form of efficient market hypothesis (EMH). If the magnitude of forecast errors in cases of (ii) and (iii) are lower than that of case (i), one can conclude that spread helps in improving accuracy of out-of-sample forecast of stock price return.

\section{Database and Research Design}

In the present study, both weekly and monthly data are used. The basic variable covered in weekly database pertain to weekly average stock price index, E/P ratio of the index portfolio and a representative interest rate from the week ended January 5, 1997 to the week ended December 31, 2007 (eleven years). The monthly database also covers these basic variables for the months from January 1996 to December 2002. The data on return and spread are derived from these basic variables.

As regards stock price index, it is preferable to choose a market representative index. In India, a number of stock price indices are available. Notable among them are BSE 30 share price index (Sensitive Index or Sensex), Economic Times 30 Index, Financial Express 30 Index, S\&P CNX NIFTY Market Index, BSE national index consisting of 100 shares (BSE-100), Economic Times 100, Financial Express 100, BSE- 200, Business Line 250, CRISIL 500 index and several other regional exchange indexes. In an interesting study, Balasubramanian and Narasimhan (1999) made an attempt to assess to what extent various indices reflect the market performance. Accordingly, they analysed in detail, various aspects of BSE Sensex, BSE-100 and BSE-200. Their empirical results suggest that there is no significant difference between these three indices.

In this study, closing value of S\&P CNX NIFTY Market Index (hereafter referred to as NSE Nifty) is considered for calculating stock market return. The data on E/P ratio pertain to NSE Nifty index portfolio. The National Stock Exchange (NSE) in India provides a fully automated screen based trading system for futures and spot market transactions, on a nationwide basis and an online monitoring and surveillance mechanism. It supports an order driven market which provides complete transparency of trading operations and operates on strict price-time priority. NSE Nifty is a well diversified 50 stock index accounting for 24 sectors of the economy. It is used for a variety of purposes such as benchmarking fund portfolios, index based derivatives and index funds. NSE Nifty is owned and managed by India Index Services and Products Ltd. (IISL), which is a joint venture between NSE and CRISIL. IISL is India's first specialised company focussed upon the index as a core product. IISL have a consulting and licensing agreement with Standard \& Poor's (S\&P), who are world leaders in index services. The base period selected for NSE Nifty index is the closing price on November 3, 1995. NSE Nifty index stocks represent about $59.49 \%$ of the total market capitalization as on May31st, 2007.

The selection of an appropriate interest rate plays a vital role; so far as the usefulness of the spread is concerned in this paper, we have used short-term rates for deriving spread. In the Indian context, possible proxies for short-term interest rate would be 'call money rate', 'yields on certain Treasury Bills', 'Deposit Rate', 'Bank Rate', etc. Among these, two rates, viz., the Bank Rate and the call money rate are generally used (Roy et al, 2000). The present study also has used the call money rate and the Bank Rate as indicators of short-term interest rate. In this study, one-period stock market return (i.e. return is weekly for weekly data, monthly for monthly data, and so on) at time point $t$, say $R_{t}$, is simply defined as $R_{t}=\log \left(P_{t}\right)-\log \left(P_{t-1}\right)$; where $P_{t}$ is a stock price index.

In Indian context, many studies (Madhusoodanan, 1998; Mohanty and Kamaiah, 2000; Samanta and Rajpathak, 2001) have used equation (3) for compilation of return series. In case of equation (3), K-period return is simply the addition of $\mathrm{k}$ consecutive one- period returns. Moreover, log-transformation also may reduce a bit of volatility/heteroscadasticity and/or may help to get normal distribution.

The information on 'spread' variable is derived by subtracting interest rate from E/P ratio associated with BSE-100 stock price index. Depending upon the proxy of interest rate, following two measures of spread are used in this study;

$\mathrm{SP}_{-} \mathrm{B}_{\mathrm{t}}=\mathrm{Eb}_{\mathrm{y}} \mathrm{P}_{\mathrm{t}}-\mathrm{BR}_{\mathrm{t}}$

$\mathrm{SP} \mathrm{C}_{\mathrm{t}}=\mathrm{Eb}_{\mathrm{y}} \mathrm{P}_{\mathrm{t}}-\mathrm{Call}_{\mathrm{t}}$

Where $S P \_B_{t}$ and $S P \_C_{t}$ are measures of spread at time $t ; b_{y} P_{t}, B R_{t}$ and $\mathrm{Call}_{t}$ are $\mathrm{E} / \mathrm{P}$ ratio, bank rate and call money rate respectively at time point $\mathrm{t}$.

\section{Empirical Results}

To start with, in Table 1, we present the estimated $\rho_{\mathrm{k}}$ for $\mathrm{k}=1,2, \ldots, 20$ ( 5 months) using weekly data. From Table 1 , it appears that the magnitude of correlation coefficient between $\mathrm{SP}_{-} \mathrm{B}_{\mathrm{t}-\mathrm{k}}$ and $\mathrm{R}_{\mathrm{t}}$ (i.e., $\rho_{\mathrm{k}}$ ) is low for $\mathrm{k}=1$ to 6 . The maximum correlation coefficient (in magnitude) is observed for $\mathrm{k}=16$ followed by $\mathrm{k}=10,9$ and 3 . In case of SP_C $\mathrm{C}_{\mathrm{t}-\mathrm{k}}$, estimated $\rho_{\mathrm{k}}$ is low for all $\mathrm{k}=1$ to 13 and the highest is evidenced for $\mathrm{k}=19$, followed by $\mathrm{k}=17,18$ and 20 . Estimates of $\rho_{\mathrm{k}}$ 's, $\mathrm{k}=1,2, \ldots, 14$, using monthly data (Table 2 ) show that the relationship between $\mathrm{SP} \mathrm{B}_{\mathrm{t}-\mathrm{k}}$ and $\mathrm{R}_{\mathrm{t}}$ is reasonably strong for $\mathrm{k}$ above 4, particularly for $\mathrm{k}=5,9,12$ and 14 . In case of SP_ $\mathrm{C}_{\mathrm{t}-\mathrm{k}}$, however, corresponding relationship is likely to be 
important only for lags $\mathrm{k}=6,9$ and 14 . It is interesting to note that the results based on monthly data are more or less consistent with the same based on weekly data, i.e., as $\mathrm{k}$ increases, the cross correlation $\left(\mathrm{s}_{\mathrm{k}}\right)$ also tends to increase.

Thus from correlation analysis, it is seen that the relationship between past values of spread and present value of stock market return is possibly strong only in longer lag, say for about 2-months or above (i.e. corresponding to 9 to 14 weeks or more). For exploring the strength in relationship between return and spread, a number of simple regression and causal-regression models are estimated and the empirical findings are interpreted. In this context, it may be noted that for estimating different regression equations (simple or causal models), lag selection is an important task.

For this purpose, we first fix an upper limit/ceiling to the maximum lag and select only the important lags within the chosen limit. In all subsequent regression/causal models, upper ceiling for maximum lag was fixed at 20 -weeks for weekly data and 14 for monthly data.

\subsection{Regression Analysis}

Initially return series was regressed on constant and own past values. Relevant empirical results (presented in Table 3) show that the underlying relationship in case of weekly data is similar (in terms of R, D-W statistics and cl statistics) with that for monthly data, though in former case $\mathrm{R}^{2}$ is relatively low. In both cases, $\mathrm{D}-\mathrm{W}$ statistics is very close to 2 (being 1.95 or more) and the Q-statistics is also insignificant at $5 \%$ level of significance (as corresponding p-value is much more than 0.05 ), indicating absence of any significant autocorrelation of the residual series.

Now, we proceed to check the robustness of the results obtained from correlation analysis. For this purpose, $\mathrm{R}_{\mathrm{t}}$ series is regressed on constant and past values of spread. Different fitted equations and associated estimates of $\mathrm{R}^{2}$, D-W statistics and Q-statistics for weekly data are given in Table 4. Similar results for monthly data are presented in Table 5. In case of weekly data, as can be seen from Table 4, SP_B has relatively stronger relationship with future return than that associated with SP_C $C_{t}$. Empirical results indicate higher $\mathrm{R}^{2}$ and better $\mathrm{D}-\mathrm{W}$ statistics when $\mathrm{R}_{\mathrm{t}}$ is regressed on constant and past values of SP_B $B_{t}$ instead of regressing $R_{t}$ on constant and past values of SP_C $C_{t}$. The Q-statistics in later case is also worse than that in former case. As a matter of fact, Q-statistics in case of SP_C $C_{t}$ is statistically significant at $5 \%$ level of significance (as corresponding p-value does not exceed 0.05), indicating presence of residual autocorrelation. In case of monthly data, the empirical results (Table 5) are almost same qualitatively as that of weekly data, though $\mathrm{R}^{2}$, D-W statistics and Q-statistics are better for monthly data. Interestingly, Q-statistics in case of SP_C for monthly data turns out to be statistically insignificant.

\subsection{Results on Causality Tests}

For exploring the possibility of causal influence of spread on return, we fitted a causal model like equation (2), where lag values of both dependent variable (i.e. $\mathrm{R}_{t}$ ) and independent variable (i.e. SP_ $\mathrm{B}_{t}$ or SP_C $\mathrm{C}_{t}$ ) are used as regressors. Different causal models are estimated by employing 'general-to-specific-type' strategy again. The estimated equations for weekly data and corresponding empirical results on causality tests are given in Table 6 and Table 7 respectively. Similar results for monthly data are presented in Table 8 and Table 9. It may be seen from Table 6 that the causal models for weekly data are generally better than the regression equations using only past values of return (as given in Table 3) or only past values of spread (given in Table 4) in terms of R 2, D-W statistics and Q-statistics.

Empirical results on causality tests using weekly data reveal that the widely used F-statistics (Table 7) is significant at 5 per cent level (as corresponding p-values are lower that 0.05 ) for both $\mathrm{SP}_{-} \mathrm{B}_{\mathrm{t}}$ and $\mathrm{SP}_{-} \mathrm{C}_{\mathrm{t}}$, indicating that weekly information on both SP_B $B_{t}$ and SP_ $C_{t}$ has causal influence on weekly return. For monthly data also, causal models are better (Table 8) than simple regression models (presented in Table 3 and Table 5). The causality tests also detected causal influence of spread on return (see Table 9), though the influence in case of SP_C $t$ is likely to be mild (as the corresponding F-statistics is insignificant at $5 \%$ level, but significant at $6 \%$ level).

\subsection{Empirical Assessment of Forecast Performance}

For assessing the forecast performance, out-of-sample forecasts of return series were generated for (i) last 20 observations in case of weekly data and (ii) last 14 observations for monthly data through rolling regression technique as discussed below. For weekly data, initially each regression/causal model (Table 4 and Table 6) was re-estimated using first 282 observations and out-of-sample forecast was generated for the return series at time point 283 . Thereafter, the coefficients of the underlying models were re-estimated using first 283 observations and out- of-sample forecast was generated for time point 284 . This way the forecasting exercise was repeated 20 times, each repetition generating a one-week ahead forecast of return series. Now comparing the forecasts of return with actual, three measure of forecast error, namely 'Mean Error (ME)', 'Mean Absolute Error (MAE)' and 'Root-Mean-Square Error (RMSE)' were calculated. Similar error measures were also derived for the random walk model. The relevant results are reported in Table 10. In case of monthly data, one-month ahead forecasts of return were generated for last 14 observations (i.e. from 59-th to 72-nd observations) similarly. Then, like in case of weekly data, different measures of forecast accuracy, viz., ME, MAE and RMSE, associated with different models (i.e. random walk and regression/causal models) were estimated and presented in Table 11. 
From Table 10 and Table 11, it is seen that generally causal models (using spread) outperform both random walk model and regression models (using only past values of spread as regressors as given in equation 1), in generating out-ofsample forecast of stock market return.

\section{Conclusion Remarks}

This paper studies the usefulness of the E/P ratio as an indicator of future stock market conditions. The present study employed various statistical and econometric tools for rigorously assessing the usefulness of spread in explaining stock market return. The studies finds that spread seems to have reasonably strong causal influence on return and the causal model helps achieving forecasts better than the random walk model. On theoretical plane, whether the spread between $\mathrm{E} / \mathrm{P}$ ratio and interest rate is helpful for predicting future return/movement of stock price index is a debatable issue. However, in practice, spread is frequently used by market practitioners. So far empirical evidence for the developed economies suggests that the information on spread could be useful. In case of emerging markets including India, the issue has not received adequate attention.

The empirical results presented here are tentative and further research is needed to address the issue. Particularly, there is a need to put concerted efforts to construct alternative measures of 'spread' based on different interest rates and compare their usefulness empirically in explaining and predicting future movement of stock market return in India. Some central banks' financial stability reports include measures of whether stock markets are overvalued by looking at $\mathrm{E} / \mathrm{P}$ ratios. However, the results in this paper show that the ratios are not useful in assessing the extent to which there is an overvaluation in the Indian stock market in the short run. There is also scope to assess the direction of stock market index, taking into account the set of potential macroeconomic input variables such as interest rates, consumer price index, industrial production etc.

\section{References}

Barman, R.B. (1996). What Determines the Prices of Indian Stocks: Fundamentals or Bubbles. The ICFAI Journal of Applied Finance, Vol.2, No.1, 23-42.

Barua S.K. and J.R. Varma (1994). Research on Indian Capital Market: A Review. Vikalpa. Vol. 19. No. 1. 15-31.

Campbell, J. Y., and Shiller, R. J., (1998). Valuation Ratios and the Long-Run Stock Market Outlook. The Journal of Portfolio Management. Vol. 24 No.2. 11-26.

Cutler, David M., James M. Poterba and Lawrence H. Summers (1991). Speculative Dynamics. Review of Economic Studies, Vol. 58. 529-546.

Fuller, R. J., Lex, C. H., and Levinson, M. J., (1993). Returns to E/P Strategies, Higgledy-Piggledy Growth, Analysts' Forecast Errors, and Omitted Risk Factors. The Journal of Portfolio Management, Vol. 19. No.2. 13-24.

Graham, Benjamin, David L. Dodd and Sidney Cottle, (1962). Security Analysis (4th ed.) New York: Mcgraw-Hill (3 ${ }^{\text {rd }}$ Chapter)

Lander, Joel, Athanasios Orphanides and Martha Dourogiannis (1997). Earnings Forecasts and the Predictability of Stock Returns: Evidence from Trading the S\&P. Journal of Portfolio Management. Vol. 23. No. 4.24-35.

Madhosoodanan, T. P. (1998). Investment Horizon and Volatility: An Analysis of the Indian Stock Market. The ICFAI Journal of Applied Finance. Vol. 4. No. 1. 85-97.

Mohanty, Pitabas (1997). EPS: Its Relationship with Stock Returns. Capital Markets Conference, UTI Institute of Capital Markets. Navi Mumbai. India.

Mohanty, Prabir Kumar and B. Kamaiah (2000). Volatility and Its Persistence in Indian Stock Market: A Case Study of 30 Scrips. Working Paper 53, Institute for Social and Economic Change. Bangalore. India.

Pesaran, M. Hashem and Allan Timmermann (1995). Predictability of Stock Returns: Robustness and Economic Significance. The Journal of Finance, Vol. L, No. 4. 1201-1228.

Pilbeam, Keith (1998), Finance and Financial Markets $\left(2^{\text {nd }}\right.$ ed.). New York: Macmillan Business $\left(2^{\text {nd }}\right.$ chapter)

Qi, Min (1999). Non-Linear Predictability of Stock Returns using Financial and Economic Variables. Journal of Business \& Economic Statistics. Vol. 17, No. 4. 419-429.

Qi, Min and G. S. Maddla (1999). Economic Factors and the Stock Market: A New Perspective. Journal of Forecasting. Vol. 18, No. 3. 151-166.

Rolph, Douglas and Pu Shen (1999). Do The Spreads Between the E/P Ratio and Interest Rates Contain Information on Future Equity Market Movements?. Research Working Paper, Federal Reserve Bank of Kansas City, RWP 99-03.

Roy, Allen, S. Amanulla and B. Kamaiah (2000). Indian Stock Market: A Test of a Semi-Strong Form of Efficiency. Working Paper 51, Institute for Social and Economic Change, Bangalore. 
Samanta, G. P. and Rajashree Rajpathak (2001). On Construction of a Composite Index for Predicting Stock Price Index in India. Finance India, Vol. XV, No. 2. 577-592.

Shiller, Robert J. (1993). Market Volatility ( $4^{\text {th }}$ ed.). London: The MIT Press $\left(7^{\text {th }}\right.$ chapter)

Table 1. Estimated Cross Correlation $\left(\rho_{\mathrm{K}}\right)$ Using Weekly Data

(Time Period: Week Ending $5^{\text {th }}$ Jan. 1997 to $31^{\text {st }}$ Dec. 2007)

\begin{tabular}{|c|c|c|c|c|c|}
\hline \multirow{2}{*}{$\begin{array}{c}\mathrm{K} \\
\text { (in weeks) }\end{array}$} & \multicolumn{2}{|c|}{ Estimated $\rho_{\mathrm{k}}$ Associated with * } & \multirow{2}{*}{$\begin{array}{c}\mathrm{K} \\
\text { (in weeks) }\end{array}$} & \multicolumn{2}{|c|}{ Estimated $\rho_{\mathrm{k}}$ Associated with * } \\
\hline & SP_B & SP_C & & SP_B & $\mathrm{SP} C \mathrm{C}$ \\
\hline 1. & 0.0172 & 0.0 .127 & 11. & 0.1121 & 0.0417 \\
\hline 2. & 0.0412 & 0.0210 & 12. & 0.1259 & 0.0111 \\
\hline 3. & 0.0112 & 0.0161 & 13. & 0.1322 & 0.0271 \\
\hline 4. & 0.0310 & -0.0211 & 14. & 0.1147 & 0.0312 \\
\hline 5. & 0.0512 & -0.0172 & 15. & 0.1227 & 0.0411 \\
\hline 6. & 0.0671 & -0.0141 & 16. & 0.1521 & 0.816 \\
\hline 7. & 0.1214 & -0.0217 & 17. & 0.1127 & 0.1072 \\
\hline 8. & 0.1011 & -0.0307 & 18. & 0.1090 & 0.0911 \\
\hline 9. & 0.1351 & 0.0211 & 19. & 0.1071 & 0.1217 \\
\hline 10. & 0.1421 & 0.0341 & 20. & 0.1122 & 0.0907 \\
\hline
\end{tabular}

Note : ${ }^{*} \rho_{\mathrm{k}}$ Indicates correlation coefficient between $\mathrm{SP}_{\mathrm{t}-\mathrm{k}}$ and $\mathrm{R}_{\mathrm{t}}$ where $\mathrm{SP}_{\mathrm{t}}=\mathrm{SP}_{-} \mathrm{B}_{\mathrm{t}}$ or $\mathrm{SP}_{-} \mathrm{C}_{\mathrm{t}}$

Table 2. Estimated Cross Correlation $\left(\rho_{\mathrm{k}}\right)$ Using Monthly Data

(Data Period: 5th Jan. 1997 to 31st Dec. 2007)

\begin{tabular}{|c|c|c|c|c|c|}
\hline \multirow{2}{*}{$\begin{array}{c}\mathrm{K} \\
\text { (in months) }\end{array}$} & \multicolumn{2}{|c|}{ Estimated $\rho_{\mathrm{k}}$ Associated with* } & \multirow{2}{*}{$\begin{array}{c}\text { Estimated } \rho_{\mathrm{k}} \\
\end{array}$} & SP_B & Associated with* \\
\hline 1. & 0.0922 & 0.0317 & 8 & SP_B & SP_C \\
\hline 2. & 0.0377 & -0.0219 & 9. & 0.1327 & 0.1698 \\
3. & 0.0691 & -0.0524 & 10. & 0.2143 & 0.2513 \\
4. & 0.1517 & -0.0632 & 11. & 0.1127 & 0.1784 \\
5. & 0.1789 & -0.1129 & 12. & 0.1281 & 0.1217 \\
6. & 0.1192 & 0.2427 & 13. & 0.1389 & 0.1634 \\
7. & 0.1244 & 0.1572 & 14. & 0.1472 & 0.1729 \\
\hline
\end{tabular}

Note : ${ }^{*} \rho_{\mathrm{k}}$ Indicates correlation coefficient between $\mathrm{SP}_{\mathrm{t}-\mathrm{k}}$ and $\mathrm{R}_{\mathrm{t}}$ where $\mathrm{SP}_{\mathrm{t}}=\mathrm{SP}_{-} \mathrm{B}_{\mathrm{t}}$ or $\mathrm{SP}_{-} \mathrm{C}_{\mathrm{t}}$ 
Table 3. Regression of $R_{1}$ on Own Past Values

\begin{tabular}{|c|c|c|c|c|c|c|c|}
\hline $\begin{array}{c}\text { Dependent } \\
\text { Variable }\end{array}$ & $\begin{array}{c}\text { Explanatory } \\
\text { Variable }\end{array}$ & Lags & Coefficients & t-ratio & $\begin{array}{r}-2 \\
\mathrm{R}\end{array}$ & $\begin{array}{c}\text { D-W } \\
\text { Statistics }\end{array}$ & Q-Statistics \\
\hline \multicolumn{8}{|c|}{ Using Weekly Data } \\
\hline \multirow[t]{7}{*}{$\mathrm{R}_{\mathrm{t}}$} & Constant & 0 & -0.0001 & 0.09 & .082 & 1.96 & 27.42 \\
\hline & $\mathrm{R}_{\mathrm{t}}$ & 1 & 0.1476 & 2.170 & & & \\
\hline & & 5 & 0.1654 & 2.72 & & & \\
\hline & & 9 & -0.1651 & 2.21 & & & p-value \\
\hline & & 12 & 0.1469 & -1.99 & & & $=0.9571$ \\
\hline & & 17 & 0.1387 & 2.49 & & & \\
\hline & & 20 & 0.1479 & 5.58 & & & \\
\hline \multicolumn{8}{|c|}{ Using Monthly Data } \\
\hline \multirow[t]{4}{*}{$\mathrm{R}_{\mathrm{t}}$} & Constant & 0 & 0.0107 & 0.71 & 0.105 & 1.99 & 14.22 \\
\hline & $\mathrm{R}_{\mathrm{t}}$ & 1 & 0.2917 & 1.72 & & & \\
\hline & & 4 & 0.2712 & 2.43 & & & p-value \\
\hline & & 9 & -0.3192 & -1.97 & & & $=0.9213$ \\
\hline
\end{tabular}

Table 4. Regression of $R_{t}$ on Spread - Using Weekly Data

\begin{tabular}{|c|c|c|c|c|c|c|c|}
\hline $\begin{array}{c}\text { Dependent } \\
\text { Variable }\end{array}$ & $\begin{array}{c}\text { Explanatory } \\
\text { Variable }\end{array}$ & Lags & Coefficients & t-ratio & $\begin{array}{r}-2 \\
\mathrm{~F}\end{array}$ & $\begin{array}{c}\text { D-W } \\
\text { Statistics }\end{array}$ & Q-Statistics \\
\hline \multicolumn{8}{|c|}{ Using SP_B as Proxy for Spread } \\
\hline \multirow[t]{7}{*}{$\mathrm{R}_{\mathrm{t}}$} & Constant & 0 & 0.0049 & 1.39 & 0.05 & 1.82 & 49.2 \\
\hline & SP_B ${ }_{t}$ & 1 & -0.0031 & -1.07 & & & \\
\hline & & 6 & -0.0143 & -1.42 & & & \\
\hline & & 10 & 0.0130 & 1.43 & & & p-value \\
\hline & & 14 & 0.0123 & 2.18 & & & $=0.1241$ \\
\hline & & 17 & -0.0086 & 2.25 & & & \\
\hline & & 20 & 0.0026 & 1.32 & & & \\
\hline \multicolumn{8}{|c|}{ Using SP_C as Proxy for Spread } \\
\hline \multirow[t]{3}{*}{$\mathrm{R}_{\mathrm{t}}$} & Constant & 0 & 0.0041 & 0.90 & 0.03 & 1.71 & 55.7 \\
\hline & SP_C $C_{t}$ & 11 & 0.0009 & 1.94 & & & $\mathrm{p}$-value \\
\hline & & 20 & 0.0005 & 1.00 & & & $=0.0297$ \\
\hline
\end{tabular}


Table 5. Regression of $R_{t}$ on Spread - Using Monthly Data

\begin{tabular}{|c|c|c|c|c|c|c|c|}
\hline $\begin{array}{c}\text { Dependent } \\
\text { Variable }\end{array}$ & $\begin{array}{c}\text { Explanatory } \\
\text { Variable }\end{array}$ & Lags & Coefficients & t-ratio & $\mathrm{R}^{-2}$ & $\begin{array}{c}\text { D-W } \\
\text { Statistics }\end{array}$ & Q-Statistics \\
\hline \multicolumn{8}{|c|}{ Using SP_B as Proxy for Spread } \\
\hline \multirow[t]{4}{*}{$\mathrm{R}_{\mathrm{t}}$} & Constant & 0 & 0.01792 & 1.10 & 0.14 & 1.87 & 15.79 \\
\hline & SP_B & 1 & -0.0253 & -2.44 & & & \\
\hline & & 4 & 0.0532 & 2.59 & & & p-value \\
\hline & & 7 & -0.0345 & -1.51 & & & $=0.8512$ \\
\hline \multicolumn{8}{|c|}{ Using SP_C as Proxy for Spread } \\
\hline \multirow[t]{2}{*}{$\mathrm{R}_{\mathrm{t}}$} & Constant & 0 & 0.0217 & 1.06 & 0.09 & 1.69 & 18.27 \\
\hline & $\mathrm{SP}_{-} \mathrm{C}_{1}$ & 6 & 0.0019 & 2.07 & & & $\begin{array}{l}\text { p-value } \\
=0.5317\end{array}$ \\
\hline
\end{tabular}

Table 6. Estimated Causal Models - Using Weekly Data

\begin{tabular}{|c|c|c|c|c|c|c|c|}
\hline $\begin{array}{c}\text { Dependent } \\
\text { Variable }\end{array}$ & $\begin{array}{c}\text { Explanatory } \\
\text { Variable }\end{array}$ & Lags & Coefficients & t-ratio & $\mathrm{R}^{-2}$ & $\begin{array}{c}\text { D-W } \\
\text { Statistics }\end{array}$ & Q-Statistics \\
\hline \multicolumn{8}{|c|}{ Using SP_B as Proxy for Spread } \\
\hline \multirow[t]{9}{*}{$\mathrm{R}_{\mathrm{t}}$} & Constant & 0 & 0.0061 & 1.52 & 0.13 & 2.03 & 34.92 \\
\hline & $\mathrm{R}_{\mathrm{t}}$ & 1 & 0.1328 & 2.03 & & & \\
\hline & & 2 & 0.1376 & 2.06 & & & \\
\hline & & 5 & -0.1076 & -1.59 & & & $\mathrm{p}$-value \\
\hline & & 8 & -0.1928 & 2.92 & & & 0.8972 \\
\hline & & 15 & 0.1741 & 2.42 & & & \\
\hline & & 20 & 0.1366 & 2.11 & & & \\
\hline & & 3 & -0.0068 & 2.47 & & & \\
\hline & & 10 & 0.0071 & 2.98 & & & \\
\hline \multicolumn{8}{|c|}{ Using SP_C as Proxy for Spread } \\
\hline \multirow[t]{9}{*}{$\mathrm{R}_{\mathrm{t}}$} & Constant & 0 & 0.0019 & 0.73 & 0.13 & 1.98 & 27.86 \\
\hline & $\mathrm{R}_{\mathrm{t}}$ & 1 & 0.1278 & 2.00 & & & \\
\hline & & 2 & 0.1620 & 2.50 & & & \\
\hline & & 7 & -0.1490 & -2.32 & & & \\
\hline & & 13 & 0.1294 & 2.17 & & & $\mathrm{p}$-value \\
\hline & & 16 & 0.1789 & 2.58 & & & 0.9817 \\
\hline & & 20 & 0.1488 & 2.41 & & & \\
\hline & & 13 & 0.0010 & 2.07 & & & \\
\hline & & 20 & 0.5003 & 1.19 & & & \\
\hline
\end{tabular}


Table 7. Results on Causality Tests - Using Weekly Data

\begin{tabular}{|c|c|c|c|c|}
\hline \multirow{2}{*}{$\begin{array}{l}\text { Dependent } \\
\text { Variable }\end{array}$} & \multirow{2}{*}{$\begin{array}{l}\text { Explanatory } \\
\text { Variable }\end{array}$} & \multirow{2}{*}{ Lags * } & \multicolumn{2}{|c|}{$\begin{array}{c}\text { Testing Hypothesis: Coefficients of SP_B/SP_C } \\
\text { Care Collectively Zero }\end{array}$} \\
\hline & & & F-Statistics & P-Value \\
\hline \multirow[t]{3}{*}{$\mathrm{R}_{\mathrm{t}}$} & Constant & & 6.1927 & 0.0058 \\
\hline & $\mathrm{R}_{\mathrm{t}}$ & $1,2,5,12,17,20$ & & \\
\hline & $\mathrm{SP}_{-} \mathrm{B}_{\mathrm{t}}$ & 3,10 & & \\
\hline \multicolumn{5}{|c|}{ Using SP_C as proxy for spread } \\
\hline \multirow[t]{3}{*}{$\mathrm{R}_{\mathrm{t}}$} & Constant & 0 & 5.2978 & \\
\hline & $\mathrm{R}_{\mathrm{t}}$ & $1,2,5,12,17,20$ & & 0.0417 \\
\hline & $\mathrm{SP}_{-} \mathrm{C}_{\mathrm{t}}$ & 11,20 & & \\
\hline
\end{tabular}

Note: * Estimated Coefficient and Corresponding t-ratios for different lags are given in Table 6.

Table 8. Estimated Causal Models - Using Monthly Data

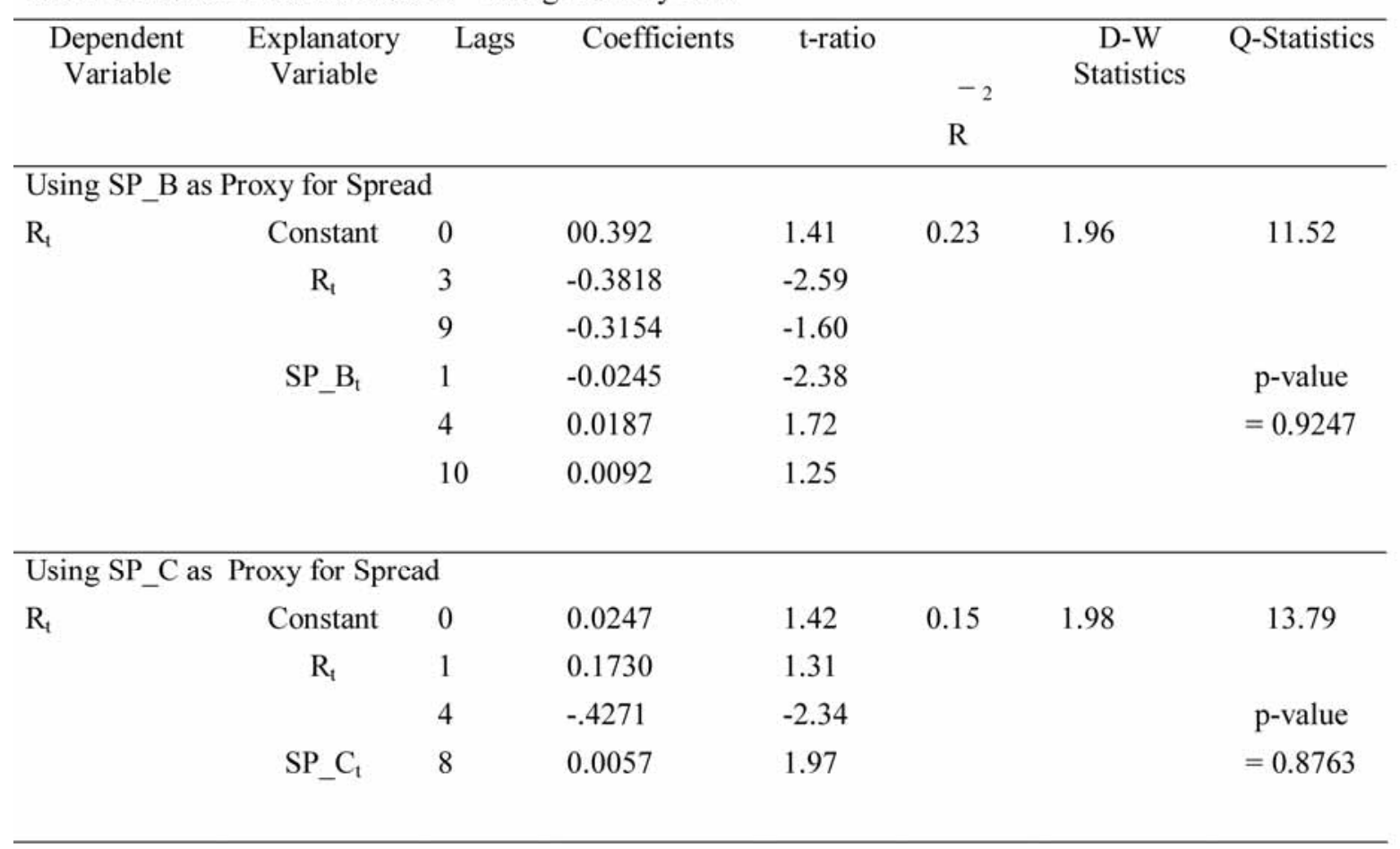


Table 9. Results on Causality Tests - Using Monthly Data

\begin{tabular}{ccccc}
\hline Dependent Variable & $\begin{array}{c}\text { Explanatory } \\
\text { Variable }\end{array}$ & Lags \# & \multicolumn{2}{c}{$\begin{array}{c}\text { Testing Hypothesis: Coefficients of } \\
\text { SP_B/SP_C are Collectively Zero }\end{array}$} \\
\cline { 3 - 5 } & & & F-Statistics & P-Value \\
\hline Using SP_B as proxy for spread & & 0 & 4.9721 & 0.0312 \\
$\mathrm{R}_{\mathrm{t}}$ & $\begin{array}{c}\text { Constant } \\
\mathrm{R}_{\mathrm{t}}\end{array}$ & 4,8 & & \\
& $\mathrm{SP}_{-} \mathrm{B}_{\mathrm{t}}$ & $1,4,9$ & & 0.0579 \\
$\begin{array}{c}\text { Using SP-C as Proxy for Spread } \\
\mathrm{R}_{\mathrm{t}}\end{array}$ & $\begin{array}{c}\text { Constant } \\
\mathrm{R}_{\mathrm{t}}\end{array}$ & 0 & 3.9243 & \\
& $\mathrm{SP}_{-} \mathrm{C}_{\mathrm{t}}$ & 2,5 & & \\
\hline
\end{tabular}

Note: “\#’ Estimated Coefficients and corresponding t-ratio for different lags are given in Table 8.

Table 10. Out-of-Sample Forecast Errors - Using Weekly Data

\begin{tabular}{|l|c|c|c|}
\hline \multicolumn{1}{|c|}{ Model } & \multicolumn{3}{c|}{ Measure of Forecast Error } \\
\cline { 2 - 4 } & ME & MAE & RMSE \\
\hline Random Walk & -0.0089 & 0.0419 & 0.0472 \\
Regression Model (As in Equation 1) & & & 0.0449 \\
Using SP_B as Proxy for Spread & -0.0079 & 0.0472 & 0.0417 \\
Using SP_C as Proxy for Spread & -0.0031 & 0.0491 & \\
Casual Model (As in Equation 2) & & & 0.0279 \\
Using SP_B as Proxy for Spread & -0.0047 & 0.0321 & 0.0307 \\
Using SP_C as Proxy for Spread & 0.0021 & 0.0312 & \\
\hline
\end{tabular}

Table 11.Out-of-Sample Forecast Errors - Using Monthly Data

\begin{tabular}{|l|c|c|c|}
\hline \multicolumn{1}{|c|}{ Model } & \multicolumn{3}{c|}{ Measure of Forecast Error } \\
\cline { 2 - 4 } & ME & MAE & RMSE \\
\hline Random Walk & -0.0212 & 0.1121 & 0.1391 \\
Regression Model (As in Equation 1) & & & \\
Using SP_B as Proxy for Spread & -0.0150 & 0.1017 & 0.1267 \\
Using SP_C as Proxy for Spread & -0.0009 & 0.1082 & 0.1357 \\
Casual Model (As in Equation 2) & & & \\
Using SP_B as Proxy for Spread & -0.0112 & 0.0815 & 0.0965 \\
Using SP_C as Proxy for Spread & -0.0027 & 0.0917 & 0.0889 \\
\hline
\end{tabular}

